\title{
Olfactory dysfunction as a screening tool for mild and moderate cases of COVID-19: a single-center prevalence study of 646 patients in flu clinic
}

\author{
Anshika Harit ${ }^{1,2^{*}}$, Pankaj Kumar ${ }^{1}$ and Ravi Prakash Jha ${ }^{2}$
}

\begin{abstract}
Background: To evaluate the prevalence of olfactory dysfunction (OD) in the Indian population and to establish olfactory dysfunction as a screening tool in COVID-19-positive patients. Data was collected using a questionnaire from laboratory-confirmed COVID-19 patients. The patient's demographic and clinical details were analyzed to calculate the prevalence of olfactory dysfunction, general symptoms like fever, cough, malaise, diarrhea, along with the sinonasal symptoms. All the symptoms were self-reported, and no objective tests were carried out.

Results: Out of 646 laboratory-confirmed cases of COVID-19 infection, olfactory dysfunction was self-reported by 465 (72\%) patients and gustatory dysfunction (GD) was seen in 406 (62.8\%) patients. The affected males (416) were proportionately more than females (230), with the mean age of our study population being $39.47 \pm 13.85$ (range $18-85$ years). The most common symptoms were myalgia $(n=494,76.5 \%)$, cough $(n=471,72.9 \%)$, and fever $(n=444$, 68.7\%). Out of 465 patients with olfactory dysfunction, only 108 (23.2\%) reported nasal obstruction. Five hundred thirty-three (82.5\%) RT-PCR-positive patients did not give a history of smoking; however, co-morbidity was reported by 163 patients, of which 117 were found to have olfactory dysfunction. One hundred seventy (26.3\%) patients gave a positive contact history.

$13.6 \%$ reported olfactory dysfunction as their first symptom. A positive association was seen between olfactory dysfunction and gustatory dysfunction
\end{abstract}

Conclusions: Our study demonstrates a high prevalence of $72 \%$ in the Indian population. We recommend that anosmia be used as a screening tool to identify mild to moderate cases of COVID-19.

Keywords: Olfactory dysfunction, COVID-19, Anosmia, SARS-CoV-2, Smell dysfunction

\section{Background}

December 2019 saw a significant portion of the Chinese population to get afflicted with lower respiratory tract illnesses. The causal agent identified as novel severe acute respiratory syndrome (SARS-CoV-2), was first reported

\footnotetext{
*Correspondence: anshika.harit@gmail.com

${ }^{2}$ Department of Community Medicine, Dr. Baba Saheb Ambedkar

Medical College and Hospital, Rohini, Delhi 110085, India

Full list of author information is available at the end of the article
}

from Wuhan, China [1]. WHO labeled COVID-19 (Coronavirus Disease-2019) as a global pandemic on 11 March 2020, as the infection rapidly spread across Asia, Europe, and America [2]. Variants of SARS-CoV were responsible for the Middle East respiratory syndrome in 2012-2013 (MERS-CoV) and SARS-CoV in 2002-2003 in China [3].

The initial presenting symptoms are fever, dry cough, dyspnea, and in severe cases, acute respiratory distress syndrome $[1,4]$. Real-time reverse transcriptase-polymerase chain reaction (RT-PCR) technique and chest 
computed tomography $(\mathrm{CT})$ are the standard diagnostic techniques $[5,6]$. The other frequently reported manifestations of COVID-19 are anosmia/hyposmia, dysgeusia, diarrhea, headache, and myalgia [4]. The first notable Asian literature evaluating chemosensory dysfunction in COVID-19 patients did not report a substantial prevalence of hyposmia/anosmia in the Chinese population [7]. However, Lechein et al. reported a prevalence of $85.6 \%$ among their study population in their sizeable multicenter trial [8].

Our study aims to evaluate the prevalence of olfactory dysfunction (OD) in lab-confirmed cases of COVID-19 presenting to our hospital and establish OD as a screening tool to identify COVID-19 cases early.

\section{Methods}

We conducted a single-center cross-sectional study research study in our hospital's flu clinic after procuring approval from the institute's ethics committee (F.5(50)/2020/BSAH/DNB/Committee/8218-8221). The flu clinic was made during the pandemic and all the patients who presented with fever and/or cough were directed to the clinic for initial evaluation and RT-PCR. Patients with respiratory distress were directed to the emergency for oxygen support and admission.

Only mild to moderate forms of coronavirus disease were considered for this study as it seemed ethically difficult to investigate olfactory and gustatory function in patients with severe life threatening infections.
Six thousand six hundred twenty-seven patients attended the clinic for screening from 15 April till 15 May 2021. Samples were collected using nasopharyngeal and throat swabs. Out of the total patients screened, 693 had positive real-time reverse transcriptase-polymerase chain reaction (RT-PCR) results.

Inclusion criteria entailed patients aged 18 and above, patients with mild to moderate disease which could independently fill out the questionnaire. We excluded patients with pre-existing smell disorders/taste disturbances, history of nasal surgery, head injury, psychiatric illness, chronic nasal disease, and severe cases requiring hospital admission or intensive care. On applying the inclusion criteria, our sample size came out to be 646. All the participants gave their informed written consent for the research study.

\section{Data collection}

The patient filled out a questionnaire designed by the institution before the RT-PCR test. In the first section of the pro forma, the patients provided their demographic and epidemiological details like age/gender/address/ identification proof. The second section dealt with the patient's primary complaint, contact history, and any associated co-morbidities. The clinician filled out the patient's vitals and the treatment advice at the end of the form. The patient's symptoms were self-reported, and we did not conduct any objective tests to assess olfactory functions. Any information gap was covered by

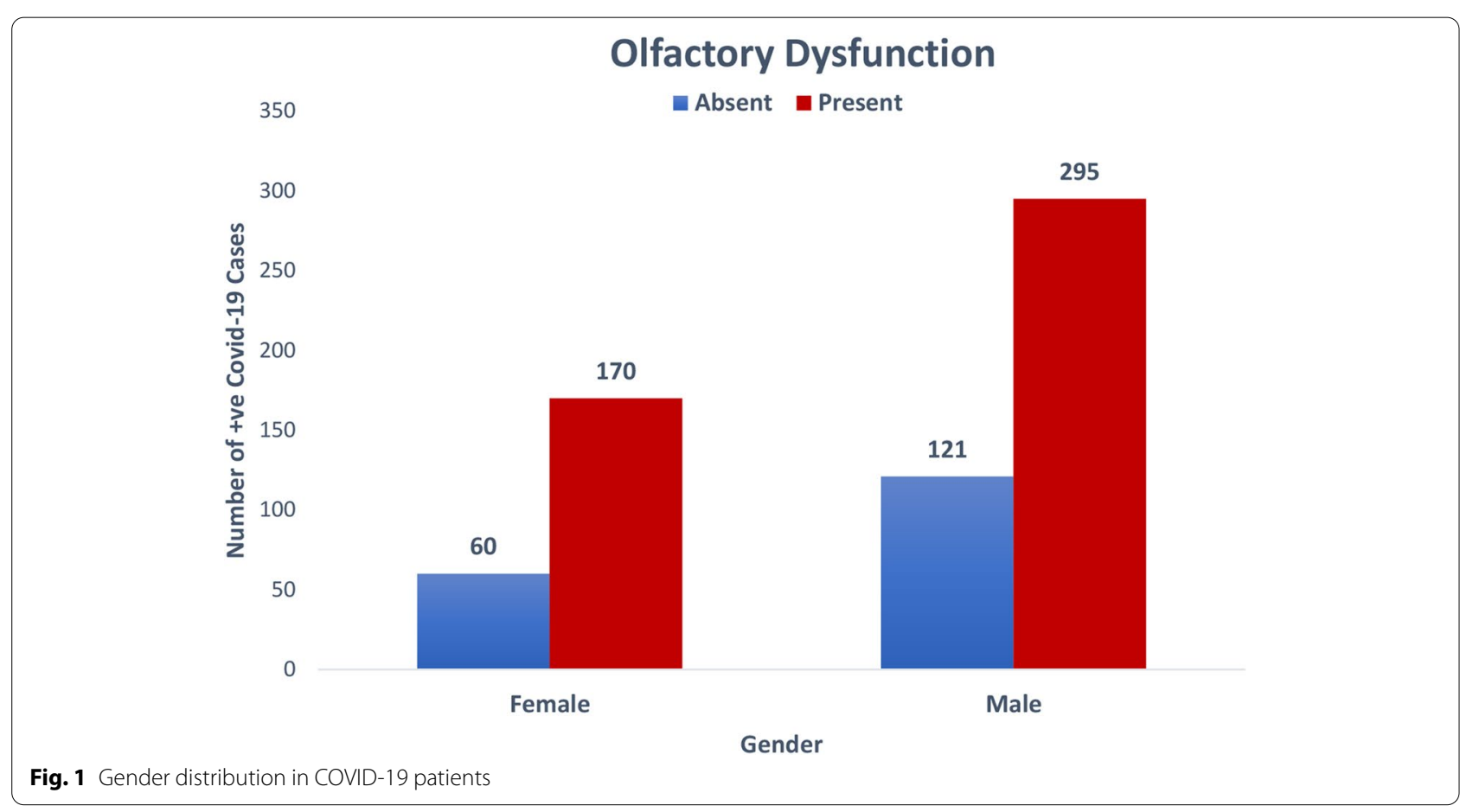


Table 1 Demographic and clinical characteristics of COVID-19 patients

\begin{tabular}{|c|c|}
\hline Variables & $\begin{array}{l}\text { Frequency } \\
(\%) / \\
\text { Mean } \pm \text { S.D. }\end{array}$ \\
\hline \multicolumn{2}{|l|}{ Gender } \\
\hline Female & $230(35.6)$ \\
\hline Male & $416(64.4)$ \\
\hline Age & $39.47 \pm 13.85$ \\
\hline $18-30$ years & $187(29.0)$ \\
\hline $30-60$ years & $395(61.1)$ \\
\hline 60 years and above & $64(9.9)$ \\
\hline \multicolumn{2}{|l|}{ Olfactory dysfunction } \\
\hline Absent & $181(28.0)$ \\
\hline Present & $465(72.0)$ \\
\hline \multicolumn{2}{|l|}{ Gustatory dysfunction } \\
\hline Absent & $240(37.2)$ \\
\hline Present & $406(62.8)$ \\
\hline \multicolumn{2}{|l|}{ Fever } \\
\hline Absent & 202 (31.3) \\
\hline Present & $444(68.7)$ \\
\hline \multicolumn{2}{|l|}{ Myalgia } \\
\hline Absent & $152(23.5)$ \\
\hline Present & $494(76.5)$ \\
\hline \multicolumn{2}{|l|}{ Cough } \\
\hline Absent & $175(27.1)$ \\
\hline Present & $471(72.9)$ \\
\hline \multicolumn{2}{|l|}{ Dyspnea } \\
\hline Absent & $372(57.6)$ \\
\hline Present & $274(42.4)$ \\
\hline \multicolumn{2}{|l|}{ Headache } \\
\hline Absent & $278(43.0)$ \\
\hline Present & $368(57.0)$ \\
\hline \multicolumn{2}{|l|}{ Sore throat } \\
\hline Absent & $313(48.5)$ \\
\hline Present & $333(51.5)$ \\
\hline \multicolumn{2}{|l|}{ Nasal obstruction } \\
\hline Absent & 497 (57.6) \\
\hline Present & $149(42.4)$ \\
\hline \multicolumn{2}{|l|}{ Rhinorrhea } \\
\hline Absent & $410(63.5)$ \\
\hline Present & $236(36.5)$ \\
\hline \multicolumn{2}{|l|}{ Diarrhea } \\
\hline Absent & $402(62.2)$ \\
\hline Present & $244(37.8)$ \\
\hline \multicolumn{2}{|l|}{ Smoking } \\
\hline Absent & $533(82.5)$ \\
\hline Present & 113 (17.5) \\
\hline \multicolumn{2}{|l|}{ Co-morbidity } \\
\hline Yes & $163(25.2)$ \\
\hline No & $483(74.8)$ \\
\hline
\end{tabular}

Table 1 (continued)

\begin{tabular}{ll}
\hline Variables & $\begin{array}{l}\text { Frequency } \\
(\%) / \\
\text { Mean } \pm \text { S.D. }\end{array}$ \\
\hline Contact history & \\
Yes & $170(26.3)$ \\
No & $476(73.7)$ \\
\hline
\end{tabular}

telephonic conversation. Subject experts analyzed the questionnaire to maximize the data output.

\section{Statistical methods}

Descriptive statistics of the patient's demographic characteristics and clinical features were calculated according to mean \pm standard deviation (SD) in case of continuous variable, whereas frequency and percentage are provided in the case of a qualitative variable. A bar diagram was used to show the frequency of various self-reported symptoms. A clustered bar diagram was made to see the total number of positive COVID-19 cases among subgroups of gender and age group. Independent-sample $t$ test was used for the comparison of the means. A chi-square test was applied to check the association between the categorical variables. A $p$ value of less than 0.05 was considered statistically significant. All the Statistical analysis was performed using SPSS 26.0 (IBM, Armonk, New York).

\section{Results}

A total of 646 RT-PCR confirmed COVID-19 patients aged 18 and above were enrolled for the study. The authors took clearance from the institution's ethical committee after a detailed presentation of the proposed research. Of that 646 laboratory-confirmed cases of COVID-19 infection, 416 were male, and 230 were female (Fig. 1). The mean age of our study population was $39.47 \pm 13.85$ (range 18-85 years) (Table 1). Majority of the patients were in 30-60years age bracket.

Olfactory dysfunction (OD) and gustatory dysfunction (GD) was self-reported by 465 (72\%) and 406 (62.8\%) patients respectively. Other frequent symptoms were myalgia $(n=494,76.5 \%)$, cough $(n=471,72.9 \%)$, fever $(n=444,68.7 \%)$, headache $(n=368,57 \%)$, dyspnea $(n=274,42.4 \%)$, diarrhea $(n=244,37.8 \%)$ (Table 1$)$ (Fig. 2). Apart from OD, otolaryngological manifestations like sore throat $(n=333,51.5 \%)$, rhinorrhea $(n=236$, $36.5 \%)$ and nasal obstruction $(n=149,42.4 \%)$ were also reported (Table 1).

However, out of 465 patients of OD, only 108 (23.2\%) reported nasal obstruction. Moreover, rhinorrhea and 


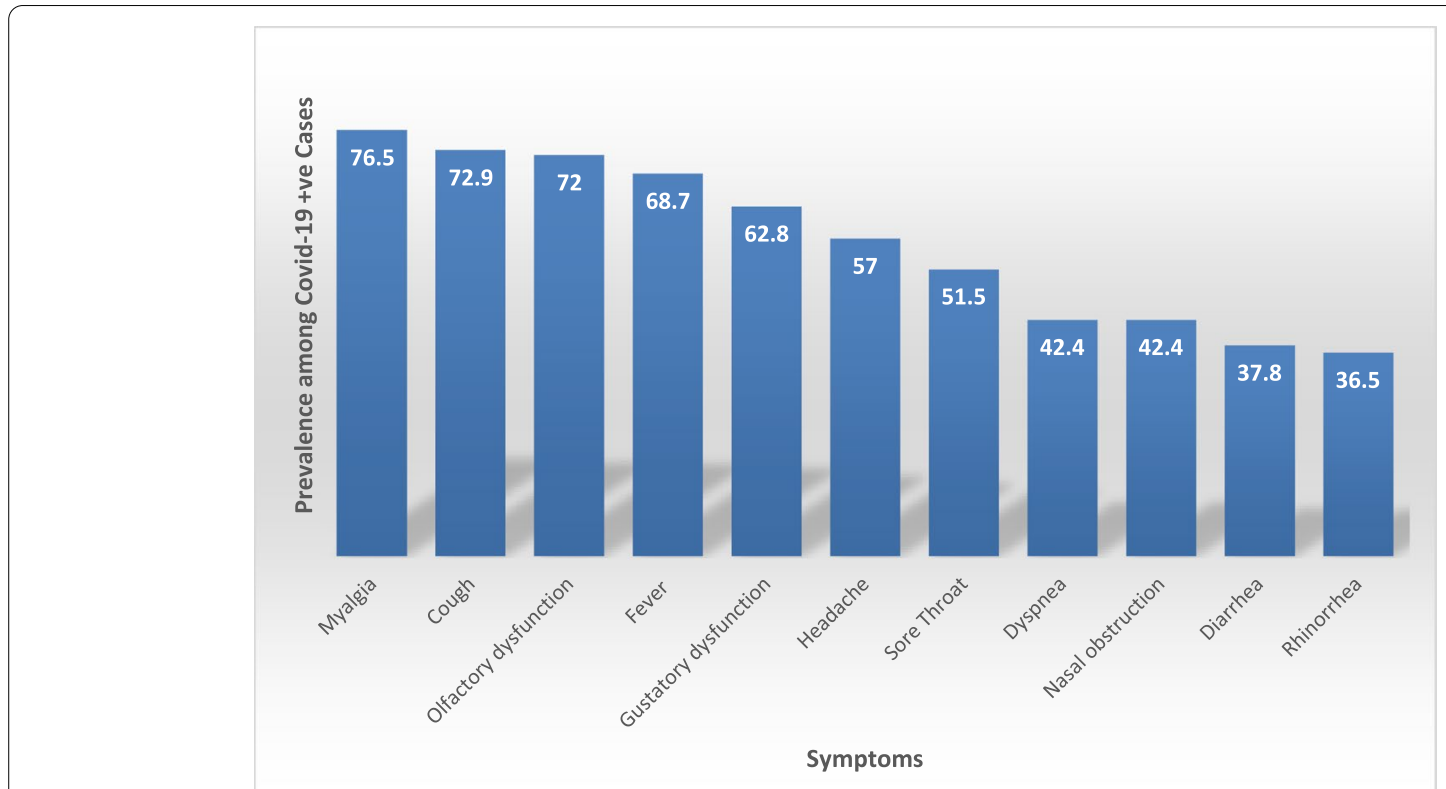

Fig. 2 Bar chart depicting the prevalence of symptoms in COVID-19 patients

Table 2 Prevalence of sinonasal symptoms in COVID-19 patients with olfactory dysfunction

\begin{tabular}{ll}
\hline Variables & $\boldsymbol{N}(\%)$ \\
\hline Sore throat & \\
Absent & $228(49.0)$ \\
Present & $237(51.0)$ \\
Nasal obstruction & \\
Absent & $357(76.8)$ \\
Present & $108(23.2)$ \\
Rhinorrhea & \\
Absent & $297(63.9)$ \\
Present & $168(36.1)$ \\
\hline
\end{tabular}

sore throat was seen in $36.1 \%$ and $51 \%$ patients respectively (Table 2).

In the present study, 533 (82.5\%) PCR-positive patients did not report any history of smoking (Table 1). Out of which, 74 (65.5\%) had associated smell disturbance. Underlying co-morbidity was reported by 163 patients of COVID-19 patients, of which 117 had OD (Table 3).

The most common underlying disease was hypertension, followed by diabetes, thyroid disease, and coronary artery disease (Table 4).

One hundred seventy (26.3\%) patients gave a positive contact history (Table 1).

No significant association was present between olfactory loss/gustatory dysfunction and age, gender, smoking, or contact history (Table 2, Table 5).
Out of the 465 patients, $13.6 \%$ reported OD as their first symptom. $59.4 \%$ of the cases with hyposmia/anosmia had associated dysgeusia (Table 6).

\section{Discussion}

Wuhan City in China reported the first known case of COVID-19 infection in December 2019 [9]. The disease has rapidly spread across continents and has already caused over a million deaths across the world (https:// covid19.who.int/). Human-to-human transmission of the SARS-CoV-2 is possible via respiratory droplets, contact with an infected individual, or touching surfaces contaminated by SARS-CoV-2. The virus is detected using the RT-PCR technique. Samples collection is done using nasopharyngeal/oropharyngeal swabs [10].

COVID-19 majorly involves the lower respiratory tract and presents with a broad clinical spectrum ranging from no symptoms to fever, cough, dyspnea, which may rapidly progress to acute respiratory distress syndrome (ARDS) and death. Other frequently reported symptoms are malaise, myalgia/arthralgia, and diarrhea [11].

Mao et al. published one of the first reports of chemosensory dysfunction in COVID-19 patients from Asia. He reported hypogeusia in $5.6 \%$ and hyposmia in $5.1 \%$ cases. However, subsequent reports published in the European literature reported a higher prevalence of anosmia and dysgeusia [7].

A review article published in the initial phase of the pandemic by El-Anwar et al. compared the results of 
Table 3 Association of demographic variables with olfactory dysfunction

\begin{tabular}{|c|c|c|c|c|}
\hline Variables & $\begin{array}{l}\text { Without olfactory dysfunction } \\
(n=181) \text { Number (\%) }\end{array}$ & $\begin{array}{l}\text { With olfactory dysfunction ( } n=465) \\
\text { number }(\%)\end{array}$ & Total & $p$ value \\
\hline Mean age & $39.75 \pm 13.71$ & $39.37 \pm 13.91$ & & 0.293 \\
\hline \multicolumn{5}{|l|}{ Age groups } \\
\hline 18-30years & $49(26.2)$ & $138(73.8)$ & $187(28.9)$ & \multirow[t]{3}{*}{0.719} \\
\hline $30-60$ years & $112(28.4)$ & $283(71.6)$ & $395(61.1)$ & \\
\hline 60 years and above & $20(31.3)$ & $44(68.8)$ & $64(9.9)$ & \\
\hline \multicolumn{5}{|l|}{ Gender } \\
\hline Female & $60(26.1)$ & $170(73.9)$ & $230(35.6)$ & \multirow[t]{2}{*}{0.416} \\
\hline Male & $121(29.1)$ & $295(70.9)$ & $416(64.4)$ & \\
\hline \multicolumn{5}{|l|}{ Smoking } \\
\hline Present & $29(25.7)$ & $84(74.3)$ & $113(17.5)$ & \multirow[t]{2}{*}{0.539} \\
\hline Absent & $152(28.5)$ & $381(71.5)$ & $533(82.5)$ & \\
\hline \multicolumn{5}{|l|}{ Co-morbidity } \\
\hline Yes & $46(28.2)$ & $117(71.8)$ & $163(25.2)$ & \multirow[t]{2}{*}{0.947} \\
\hline No & $135(28.0)$ & $348(72.0)$ & $483(74.8)$ & \\
\hline \multicolumn{5}{|l|}{ Contact history } \\
\hline Yes & $47(27.6)$ & $123(72.4)$ & $170(26.3)$ & \multirow[t]{2}{*}{0.900} \\
\hline No & $134(28.2)$ & $342(71.8)$ & $476(73.7)$ & \\
\hline
\end{tabular}

Table 4 Comorbidities seen in COVID-19 patients

\begin{tabular}{ll}
\hline Co-morbidity & $\mathbf{N}(\%)$ \\
\hline No & $483(74.8)$ \\
Hypertension & $89(13.8)$ \\
Diabetes & $40(6.2)$ \\
Thyroid & $22(3.4)$ \\
Coronary artery disease & $9(1.4)$ \\
Tuberculosis & $7(1.1)$ \\
Asthma & $7(1.1)$ \\
Chronic kidney disease & $4(0.6)$ \\
Autoimmune & $5(0.8)$ \\
COPD & $4(0.6)$ \\
Carcinoma & $3(0.5)$ \\
\hline
\end{tabular}

the various studies across the globe to see the common ENT manifestations in patients of coronavirus disease. In the analyzed results, fever and cough were dominant presentations. Among ENT manifestations, sore throat (11.3\%) and headache (10.7\%) were most commonly reported manifestation; however, olfactory dysfunction was sparsely described in the literature [12].

El-Anwar et al. also conducted a cross-sectional study on 120 patients of COVID-19 in which smell and taste dysfunction were seen in only $25 \%$ cases and the most common ENT manifestation were sore throat (30\%) and nasal and congestion (28.3\%). They also reported two unusual symptoms of tonsil enlargement and obstructive sleep apnea in $10 \%$ and $6.6 \%$ of their subjects respectively [13]. However, the most prominent ENT manifestations in our study were olfactory $(72 \%)$ and gustatory dysfunction (62.8\%), respectively. Also, none of our patients reported tonsil enlargement or obstructive sleep apnea.

A large retrospective multicenter European study conducted by Lechein reported olfactory dysfunction in $85.6 \%$ of patients and taste disturbances in $88 \%$ of cases. Four hundred seventeen lab-confirmed cases of COVID19 participated in this study, out of which $11.8 \%$ of the patients reported olfactory dysfunction as their first symptom. Our results were comparable to the study conducted by Leichen et al., as $13.6 \%$ of cases reported OD as their primary symptom [8]. A research study conducted by Varia et al. used psycho-physiological objective tests of anosmia on 72 patients, out of which $18.1 \%$ of cases reported olfactory dysfunction as their first symptom [14].

Klopfenstein et al., in their research paper, retrospectively observed features of anosmia in 114 patients. $47 \%$ of the patients reported anosmia. Fatigue (93\%), cough (87\%), fever $(74 \%)$, headache $(82 \%)$, myalgia $(74 \%)$, and diarrhea (52\%) were predominant symptoms. Our study results were in line with Klopfenstein's findings, with myalgia (76.5\%), cough $(72.9 \%)$, and fever $(68.7 \%)$ being the most typical systemic manifestations. Also, OD was associated with GD in 59.4\% of cases [15].

Another similarity to this study was the frequency of sinonasal symptoms like nasal obstruction and 
Table 5 Association of demographic variables with gustatory dysfunction

\begin{tabular}{|c|c|c|c|c|}
\hline Variables & $\begin{array}{l}\text { Without gustatory dysfunction } \\
(n=240) \\
\text { number }(\%)\end{array}$ & $\begin{array}{l}\text { With Gustatory dysfunction }(n=406) \\
\text { number }(\%)\end{array}$ & Total & $p$ value \\
\hline Mean age & $39.51 \pm 13.48$ & $39.45 \pm 14.07$ & & 0.099 \\
\hline \multicolumn{5}{|l|}{ Age groups } \\
\hline 18-30years & $64(34.2)$ & $123(65.8)$ & $187(28.9)$ & \multirow[t]{3}{*}{0.610} \\
\hline $30-60$ years & $152(38.5)$ & $243(61.5)$ & $395(61.1)$ & \\
\hline 60 years and above & $24(37.5)$ & $40(62.5)$ & $64(9.9)$ & \\
\hline \multicolumn{5}{|l|}{ Gender } \\
\hline Female & $82(35.7)$ & $148(64.3)$ & $230(35.6)$ & \multirow[t]{2}{*}{0.558} \\
\hline Male & $158(38.0)$ & $258(62.0)$ & $416(64.4)$ & \\
\hline \multicolumn{5}{|l|}{ Smoking } \\
\hline Present & $39(34.5)$ & $74(65.5)$ & $113(17.5)$ & \multirow[t]{2}{*}{0.523} \\
\hline Absent & $201(37.7)$ & $332(62.3)$ & $533(82.5)$ & \\
\hline \multicolumn{5}{|l|}{ Co-morbidity } \\
\hline Yes & $67(41.1)$ & $96(58.9)$ & $163(25.2)$ & \multirow[t]{2}{*}{0.227} \\
\hline No & $173(35.8)$ & $310(64.2)$ & $483(74.8)$ & \\
\hline \multicolumn{5}{|l|}{ Contact history } \\
\hline Yes & $69(40.6)$ & $101(59.4)$ & $170(26.3)$ & \multirow[t]{2}{*}{0.280} \\
\hline No & $171(35.9)$ & $305(64.1)$ & $476(73.7)$ & \\
\hline
\end{tabular}

Table 6 Correlation between olfactory dysfunction and gustatory dysfunction

\begin{tabular}{|c|c|c|c|c|}
\hline Variables & $\begin{array}{l}\text { Without gustatory dysfunction } \\
(n=240) \\
\text { Number (\%) }\end{array}$ & $\begin{array}{l}\text { With gustatory dysfunction }(n=406) \\
\text { number }(\%)\end{array}$ & Total & $p$-value \\
\hline \multicolumn{5}{|c|}{ Olfactory dysfunction } \\
\hline Yes & $59(40.6)$ & $406(59.4)$ & $465(72.0)$ & 0.000 \\
\hline No & $181(35.9)$ & $0(0.0)$ & $181(28.0)$ & \\
\hline
\end{tabular}

rhinorrhea in patients with OD. Klopfenstein observed rhinorrhea in $57 \%$ and nasal obstruction in $30 \%$ cases of OD. While in our study, the prevalence of rhinorrhea and nasal obstruction were $36.1 \%$ and $23.2 \%$, respectively.

However, unlike many studies, our study had proportionately more male patients as compared to female. This result was comparable to the study carried out by $\mathrm{Al} \mathrm{Ani}$ et al., who observed that males were affected more than females. The prevalence of smokers was similar to our study [16].

Spinato et al. used the SNOT 22 grade to categorize the OD/GD into mild-moderate and severe. 64.4 and 57.3\% of patients reported disturbances in taste and smell, respectively [17].

Our results were in line with the findings of Luers et al.; the affected males were proportionately more than females. Out of the 72 patients enrolled for the study, 53 had anosmia (73.6\%), and 69.4 had GD [18].
Moein et al. reported the highest incidence of OD in all the studies reviewed. Ninety-five percent of patients reported OD [19].

On comparing our study with our Indian counterparts, Mishra et al. conducted a case-control trial with 74 patients in each group; we observed that the result of gender predisposition was similar to our observation. However, the prevalence of anosmia in their research was only $14.8 \%$ [20].

Post viral smell dysfunction is not uncommon and has been reported with the respiratory syncytial virus, influenza, and parainfluenza viruses [21]. It may be due to the olfactory cleft area's congestion and edema, secondary inflammation of the nasal mucosa, or neurological deficit due to olfactory bulb damage [22]. However, the high prevalence of anosmia associated with COVID-19 needs further in-depth evaluation. Our study results in terms of the prevalence of OD and GD are comparable to our European counterparts. 


\section{Conclusions}

Olfactory dysfunction can be the first symptom of COVID-19 and may precede the development of a more severe infection. Considering that three fourth of our study population had an alteration of smell and taste, we recommend that OD be an independent and primary criterion for suspected COVID-19 patients. Further, indepth trials utilizing objective tests should are needed for further evaluation and characterization COVID-19.

\section{Acknowledgements}

None.

\section{Authors' contributions}

$\mathrm{AH}$ was responsible for analyzing the data and writing the manuscript. PK was responsible for data collection and preparation of the final version. RPJ provided the expert statistical analysis. All authors have read and approved the final manuscript.

\section{Funding}

Not applicable.

\section{Availability of data and materials}

Patient's personal details have not been made available due to privacy concerns. However, the raw data collected from the flu clinic is available for analysis.

\section{Declarations}

\section{Ethics approval and consent to participate}

All procedures performed in studies involving human participants were in accordance with the ethical standards of the institutional and/or national research committee and with the 1964 Helsinki Declaration and its later amendments or comparable ethical standards. The ethical committee of Dr. Baba Saheb Ambedkar Medical College and Hospital, Delhi gave the ethical clearance for the research study (F.5(50)/2020/BSAH/DNB/Committee/8218-8221). Consent to participate was taken from the patients.

\section{Consent for publication}

Informed written consent was obtained from the patients for publication of this research article and any accompanying data.

\section{Competing interests}

The authors declare that they have no competing interests.

\section{Author details}

${ }^{1}$ Department of Otorhinolaryngology, Dr. Baba Saheb Ambedkar Medical College and Hospital, Rohini, Delhi 110085, India. ${ }^{2}$ Department of Community Medicine, Dr. Baba Saheb Ambedkar Medical College and Hospital, Rohini, Delhi 110085, India.

Received: 31 August 2021 Accepted: 12 November 2021

Published online: 20 December 2021

\section{References}

1. Huang C, Wang Y, Li X, Ren L, Zhao J, Hu Y et al (2020) Clinical features of patients infected with 2019 novel coronavirus in Wuhan. China Lancet 395(10223):497-506

2. Cucinotta D, Vanelli M (2020) WHO declares COVID-19 a pandemic. Acta Biomed 91(1):157-160

3. Wit de E, Doremalen van N, Falzarano D, Munster VJ. SARS and MERS: recent insights into emerging coronaviruses. Nat Rev Microbiol 2016; 14(8): 523-534

4. Rodriguez-Morales AJ, Cardona-Ospina JA, Gutiérrez-Ocampo E, Villamizar-Peña R, Holguin-Rivera Y, Escalera-Antezana JP, et al. Clinical, laboratory and imaging features of COVID-19: a systematic review and meta-analysis. Travel Med Infect Dis. 2020 Mar; 34:101623

5. Singhal T (2020) A review of coronavirus disease-2019 (COVID-19). Indian J Pediatr 87(4):281-286

6. Ai T, Yang Z, Hou H, Zhan C, Chen C, Lv W, et al. Correlation of chest CT and RT-PCR testing for coronavirus disease 2019 (COVID-19) in China: A report of 1014 Cases. Radiology. (2020). Available from: https://doi.org/10. 1148/radiol.2020200642

7. Mao L, Jin H, Wang M, Hu Y, Chen S, He Q et al (2020) Neurological manifestations of hospitalized patients with coronavirus disease 2019 in Wuhan, China: a retrospective case series study. JAMA Neurol 77(6):683-690

8. Lechien JR, Chiesa-Estomba CM, De Siati DR, Horoi M, Le Bon SD, Rodriguez A, et al. Olfactory and gustatory dysfunctions as a clinical presentation of mild-to-moderate forms of the coronavirus disease (COVID-19): a multicentre European study. Eur Arch OtoRhinoLaryngol 2020. Available from: https://doi.org/10.1007/s00405-020-05965-1

9. Wang D, Yin Y, Hu C, Liu X, Zhang X, Zhou S et al (2020) Clinical course and outcome of 107 patients infected with the novel coronavirus, SARS-CoV-2, discharged from two hospitals in Wuhan. China Critical care 24:188

10. He JL, Luo L, Luo ZD, Lyu JX, Ng MY, Shen XP et al (2020) Diagnostic performance between CT and initial real-time RT-PCR for clinically suspected 2019 coronavirus disease (COVID-19) patients outside Wuhan. China Respir Med 168:105980

11. Menni C, Valdes A, Freydin MB, Ganesh S, Moustafa JE, Visconti A, et al. Loss of smell and taste in combination with other symptoms is a strong predictor of COVID-19 infection. Nat Med. 2020. Available from: doi: https://doi.org/10.1038/s41591-020-0916-2

12. El-Anwar MW, Elzayat S, Fouad YA (2020) ENT manifestation in COVID19 patients. Auris Nasus Larynx 47(4):559-564

13. El-Anwar, Mohammad Waheed et al. Analysis of ear, nose and throat manifestations in COVID-19 patients. Int. Arch. Otorhinolaryngol [online]. 2021, v. 25, n. 3 [Accessed 16 October 2021] , pp. 343-348. Available from: <https://doi.org/10.1055/s-0041-1730456>

14. Vaira LA, Deiana G, Fois AG, Pirina P, Madeddu G, Vito De A, et al. Objective evaluation of anosmia and ageusia in COVID-19 patients: single-center experience on 72 cases. Head Neck 2020; 42:1252-1258

15. Klopfenstein T, Kadiane-Oussou NJ, Toko L, Royer PY, Lepiller Q, Gendrin $V$ et al (2020) Features of anosmia in COVID-19. Med Mal Infect 50(5):436-439

16. Al-Ani RM, Acharya D (2020) Prevalence of anosmia and Ageusia in patients with COVID-19 at a primary health center, Doha, Qatar. Indian J Otolaryngol Head Neck Surg. 19:1-7

17. Spinato G, Fabbris C, Polesel J, Cazzador D, Borsetto D, Hopkins C et al (2020) Alterations in smell or taste in mildly symptomatic outpatients with SARS-CoV-2 infection. JAMA. 323(20):2089-2090

18. Luers JC, Klussmann JP, Guntinas-Lichius O (2020) The COVID-19 pandemic and otolaryngology: what it comes down to? Laryngorhinootologie. 99:287-291

19. Moein ST, Hashemian SMR, Mansourafshar B, Khorram-Tousi A, Tabarsi P Doty RL (2020) Smell dysfunction: a biomarker for COVID-19. Int Forum Allergy Rhinol 10(8):944-950

20. Mishra P, Gowda V Dixit S, Kaushik M (2020) Prevalence of new-onset anosmia in COVID-19 patients: is the trend different between European and Indian population? Indian J Otolaryngol Head Neck Surg 72(4):484-487

21. Suzuki M, Saito K, Min W-P, Vladau C, Toida K, Itoh H et al (2007) Identification of viruses in patients with post-viral olfactory dysfunction. Laryngoscope. 117(2):272-277

22. Naeini AS, Karimi-Galougahi M, Raad N, Ghorbani J, Taraghi A, Haseli S et al (2020) Paranasal sinuses computed tomography findings in anosmia of COVID-19. Am J Otolaryngol 41(6):102636

\section{Publisher's Note}

Springer Nature remains neutral with regard to jurisdictional claims in published maps and institutional affiliations. 